\title{
Precooling and percooling (cooling during exercise) both improve performance in the heat: a meta-analytical review
}

\author{
Coen C W G Bongers, ${ }^{1}$ Dick H J Thijssen, ${ }^{1,2}$ Matthijs T W Veltmeijer, ${ }^{1}$ \\ Maria T E Hopman, ${ }^{1}$ Thijs M H Eijsvogels ${ }^{1,3}$
}

\begin{abstract}
- Additional material is published online only. To view please visit the journal online (http://dx.doi.org/10.1136/ bjsports-2013-092928).

'Department of Physiology, Radboud university medical center, Nijmegen, The Netherlands ${ }^{2}$ Liverpool John Moores University, Liverpool, UK ${ }^{3}$ Department of Cardiology, Henry Low Heart Centre, Hartford Hospital, Hartford, Connecticut, USA
\end{abstract}

\section{Correspondence to} Dr Thiijs M H Eijsvogels, Department of Physiology (392), Radboud university medical center,

P.O. Box 9101, Nijmegen 6500 HB, The Netherlands; Thijs.Eijsvogels@radboudumc.nl

Received 25 July 2013 Revised 26 November 2013 Accepted 18 January 2014 Published Online First 19 April 2014

\section{CrossMark}

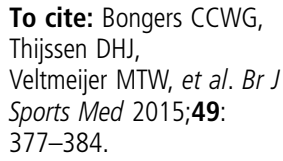

\begin{abstract}
Background Exercise increases core body temperature (Tc), which is necessary to optimise physiological processes. However, excessive increase in Tc may impair performance and places participants at risk for the development of heat-related illnesses. Cooling is an effective strategy to attenuate the increase in Tc. This meta-analysis compares the effects of cooling before (precooling) and during exercise (percooling) on performance and physiological outcomes.
\end{abstract}

Methods A computerised literature search, citation tracking and hand search were performed up to May 2013. 28 studies met the inclusion criteria, which were trials that examined the effects of cooling strategies on exercise performance in men, while exercise was performed in the heat $\left(>30^{\circ} \mathrm{C}\right)$. 20 studies used precooling, while 8 studies used percooling.

Results The overall effect of precooling and percooling interventions on exercise performance was $+6.7 \pm 0.9 \%$ (effect size $(E S)=0.43)$. We found a comparable effect $(p=0.82)$ of precooling $(+5.7 \pm 1.0 \%(E S=0.44))$ and percooling $(+9.9 \pm 1.9 \%(E S=0.40))$ to improve exercise performance. A lower finishing Tc was found in precooling $\left(38.9^{\circ} \mathrm{C}\right)$ compared with control condition $\left(39.1^{\circ} \mathrm{C}\right.$, $p=0.03$ ), while Tc was comparable between conditions in percooling studies. No correlation between Tc and performance was found. We found significant differences between cooling strategies, with a combination of multiple techniques being most effective for precooling $(p<0.01)$ and ice vest for percooling ( $p=0.02)$.

Conclusions Cooling can significantly improve exercise performance in the heat. We found a comparable ES for precooling and percooling on exercise performance, while the type of cooling technique importantly impacts the effects. Precooling lowered the finishing core temperature, while there was no correlation between Tc and performance.

\section{INTRODUCTION}

Excessively elevated core body temperature (Tc), arising from a disbalance between heat production and heat loss during prolonged exercise, has a negative impact on physiological functions and exercise performance. ${ }^{1} 2$ Moreover, an elevated Tc can even lead to the development of severe heat illnesses, such as heat stroke. ${ }^{2}$ The relevance of attenuating the increase in Tc during exercise is highlighted by the organisation of future major sport events in hot and/or humid climatic conditions (eg, Olympic Games of Rio de Janeiro 2016 and the FIFA World Cup in Brazil 2014 and Qatar 2022). Moreover, the level of performance decrement increases progressively with a rise in environmental heat stress. ${ }^{3}$ Strategies that can prevent excessive heat storage during exercise in the heat, and consequently a reduction in exercise performance, are therefore of high interest.

Cooling can be applied prior to (precooling) or during (percooling) exercise to attenuate the increase in Tc and improve exercise performance. Existing reviews and meta-analyses showed that precooling can effectively enhance exercise performance. $^{4-7}$ A substantially lower number of studies focused on cooling strategies applied during exercise: percooling. Performance benefits of precooling normally decrease after $20-25 \mathrm{~min}$ of exercise. $^{8}$ Therefore, the use of cooling techniques during an exercise bout, especially when involving endurance exercise, may elongate the duration of the beneficial effects of the cooling intervention on exercise performance. In addition to the larger 'window of opportunity' to cool the athlete, the level of thermal strain is higher during exercise compared with resting conditions. ${ }^{9}$ This suggests that cooling during exercise has a large potential in clinical practice to prevent significant thermal strain and maintain exercise performance. These cooling strategies are referred to as percooling, derived from the Latin word per meaning 'during'. Until now, relatively little is known about the impact of percooling on exercise performance, or examined the hypothesis that percooling is more effective than precooling. ${ }^{10}$

The purpose of this meta-analytical review is to compare the effects of precooling and percooling on exercise performance and on relevant thermophysiological outcomes (ie, Tc, skin temperature (Tskin) and heart rate (HR)) in healthy volunteers under hot climatic conditions. Furthermore, the effects of precooling and percooling on performance may vary between cooling techniques (cooling vests, cold water immersion, cold water ingestion, cooling packs and mixed method cooling). ${ }^{4-6} 11-13$ Better insight into these techniques is necessary to identify the 'best practice' cooling technique to improve exercise performance under hot thermal conditions. Therefore, the second aim of this study is to review the current literature on this topic and determine differences between cooling techniques.

\section{METHODS}

\section{Search strategy}

We searched PubMed and Web of Science. Ten $\mathrm{MeSH}$ terms and keywords ('exercise', 'cooling', 'performance', 'during exercise', 'precooling', 
'effects', 'ice slurry ingestion', 'cooling vest', 'cold water immersion', and 'cold water ingestion') were combined by Boolean logic (AND), and the results were limited to human subjects and articles written in English. Each database was searched from their earliest available article up to 7 May 2013. We also searched the reference lists of all incoming articles.

\section{Study selection}

Selection of publications for inclusion in this meta-analysis was based on the following criteria. First, only studies applying a cooling intervention before (precooling) or during exercise (percooling) and in a crossover design were selected. Moreover, only studies performed in hot ambient conditions with ambient temperatures $\geq 30^{\circ} \mathrm{C}$ were included. Second, only study populations comprising male adults, or studies comprising both sexes where data of male participants were reported separately, were included to avoid any potential impact of the menstrual cycle on study results. Furthermore, only studies reporting at least one outcome parameter associated with cycling or running exercise performance (eg, finish time, completed distance, time to exhaustion, power output, etc) were included in this meta-analysis. Studies that merely evaluated the effects of cooling on physiological outcomes (HR and blood lactate levels) were excluded. The first author was responsible for the study selection. After the selection process, all studies were discussed with two coauthors. In case of disagreement about the inclusion of a study, a voting process was used to determine if a study was included or not. Figure 1 provides a flow chart of our literature search.

\section{Study classification}

After inclusion, studies were classified into groups based on the following criteria. For our first aim, studies were classified based on the type of cooling (precooling vs percooling). For our

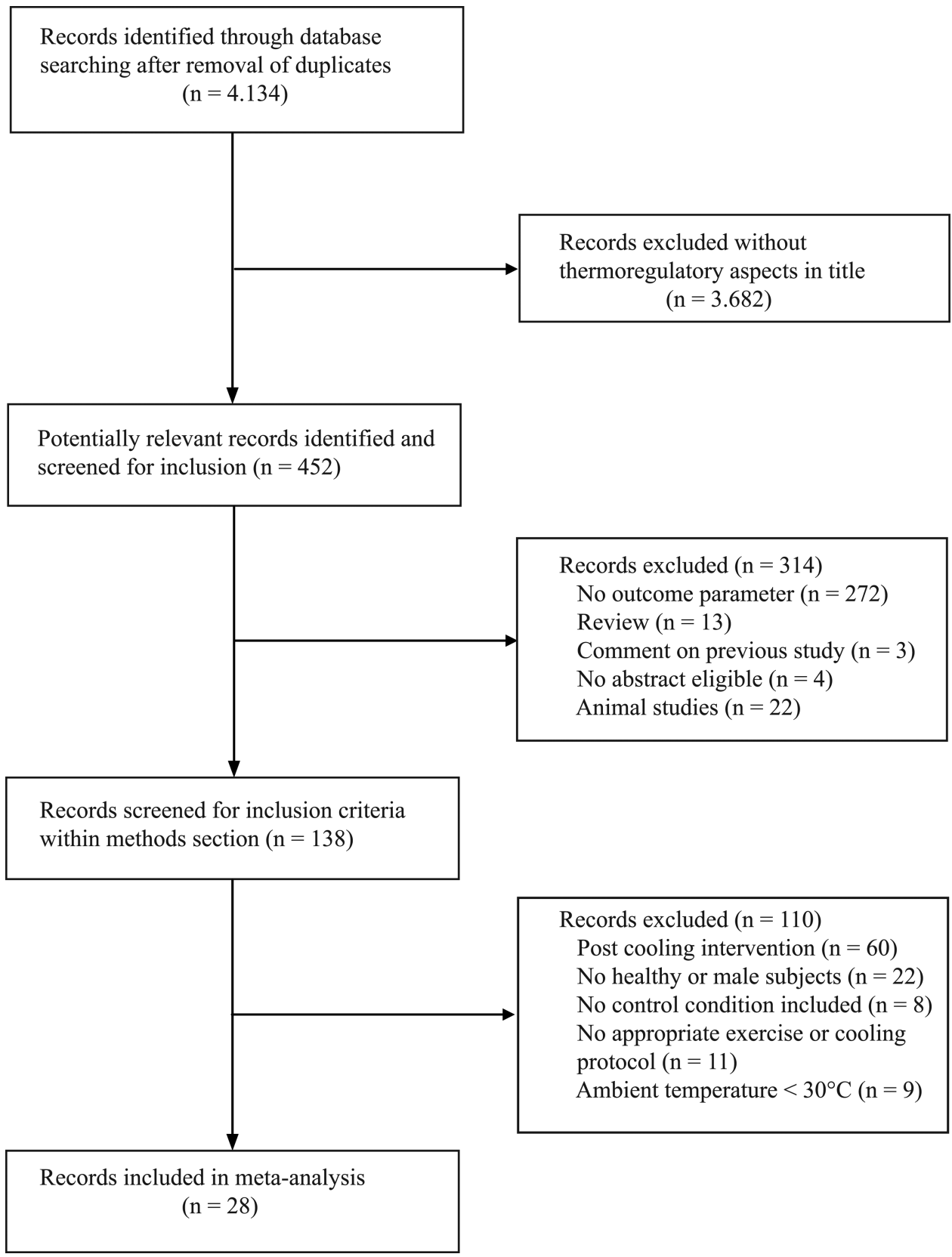

Figure 1 Overview of selection process of the included studies for this meta-analysis. N indicates the number of studies. 
second aim, studies were classified according to their cooling strategy: (1) cooling vest (ice vests and evaporative cooling vests), (2) cold water immersion, (3) cold water ingestion and/or ice slurry ingestion, (4) cooling packs and (5) mixed method cooling (combined application of two or more cooling techniques). Furthermore, studies that compared multiple cooling intervention trials with the same control condition were included more than once.

\section{Effect size assessment}

For all studies that were included, standardised mean differences (effect size (ES) in Hedge's g) and 95\% CIs were calculated for continuous outcomes using the Cochrane Collaboration's software Review Manager V.5.1.0 (Cochrane IMS, Melbourne, Australia). Statistical analyses were also performed using this software, with the significance level set at $p<0.05$. The calculations in this program were based on the difference in outcome between the intervention and the control conditions. To calculate the SE, we needed the exact $p$ value (for calculation of the $t$ value). When the $p$ value was not provided, we contacted the corresponding author. However, if this information could not be provided or the author did not respond, we used $p=0.049$ and $\mathrm{p}=0.051$ for $\mathrm{p}<0.05$ and $\mathrm{p}>0.05$, respectively. This progressive approach avoids an overestimation of the effect of cooling. However, as it may also cause a selection bias, we performed a subanalysis including only studies that provided the exact $\mathrm{p}$ values.

Negative effects of cooling were indicated with a minus sign. Data for all single studies and weighted average values were presented as mean $\pm \mathrm{SD}$. The interpretation of the ES was based on the following scale: $0-0.19=$ negligible effect, $0.20-0.49=$ small effect, $0.50-0.79=$ moderate effect and $\geq 0.80=$ large effect. ${ }^{14}$ The presence of publication bias was established by evaluating Begg's funnel plot asymmetry ${ }^{15}$ and Egger's linear regression test, ${ }^{16}$ in which $\mathrm{p}<0.05$ was considered significant. ${ }^{17}$

\section{Physiological parameters}

We included Tc, Tskin and HR in this meta-analysis. Data were extracted from the text, tables or figures (using GetData Graph Digitizer software V.2.26). The effect of the cooling intervention was calculated by subtracting data of the cooling condition from the control condition ( $\Delta \mathrm{Tc}, \Delta \mathrm{Tskin}$ and $\Delta \mathrm{HR}$ ). Correlations between the change in physiological responses and the relative change in performance were calculated using SPSS V.20.0 (SPSS, Chicago, USA), and the level of significance was set at $\mathrm{p}<0.05$. Student paired $t$ tests were used to examine differences in finishing Tc, Tskin and HR between the cooling and the control conditions.

\section{RESULTS}

\section{Included studies}

A total of 28 manuscripts that met our inclusion criteria ${ }^{11} 1218-43$ were identified. Some of these studies compared multiple cooling interventions and were therefore included more than once, which resulted in a total of 36 studies with a total number of 323 participants. Characteristics of the included studies are summarised in the online supplementary table $\mathrm{S} 1$. The average sample size was 9 , while the largest study was based on 20 participants. The weighted average improvement of the cooling strategies on exercise performance in all studies was $6.7 \pm 0.9 \%$ and the weighted average ES was $0.43 \pm 0.06$. A funnel plot of all studies demonstrates the presence of publication bias due to asymmetry (figure 2). The publication bias was confirmed by a statistically significant Egger's test $(p<0.01)$ and a significant Begg's funnel plot $(p=0.01)$. The subanalysis, in which the studies with exact $\mathrm{p}$ values were included

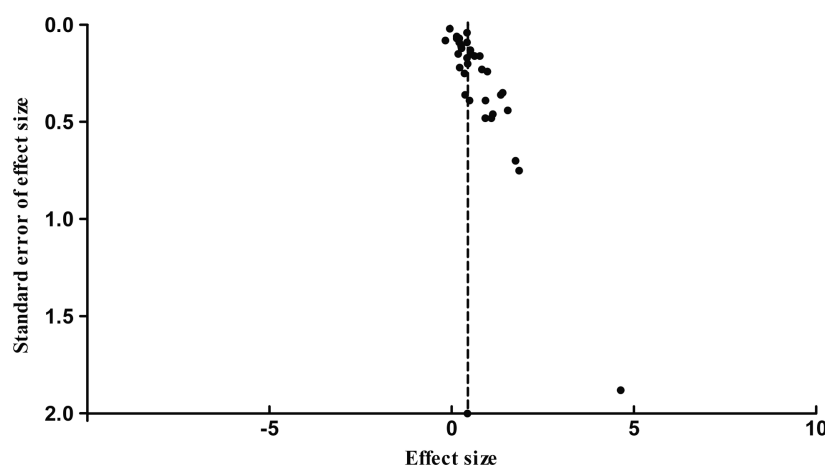

Figure 2 The funnel plot analysis indicated a possible presence of publication bias due to the asymmetrical shape. The vertical dotted line represents the weighted average effect size of all included studies. The $x$-axis showed the effect size, and the $y$-axis the SE of the effect size.

only, did not alter the outcomes of the original analysis. Therefore, only data from the initial analysis are provided.

\section{Precooling versus percooling}

Twenty-seven studies applied a precooling intervention and nine studies applied percooling (figure 3). The weighted average exercise performance improvement of precooling was $5.7 \pm 0.9 \%$ $(\mathrm{ES}=0.44)$ and for percooling interventions it was $9.9 \pm 1.9 \%$ $(E S=0.40)$. We found no significant difference in ES for both types of cooling on exercise performance in the heat $(p=0.82)$.

\section{Effects on physiological parameters}

Table 1 shows an overview of the (change in) physiological parameters during the control and cooling conditions. We found a significantly lower finishing $\mathrm{Tc}$ in the precooling $\left(38.9^{\circ} \mathrm{C}\right)$ condition compared with the control $\left(39.1^{\circ} \mathrm{C}, \mathrm{p}=0.03\right)$, while $\mathrm{Tc}$ was comparable for the percooling studies. Tskin and HR did not differ between the cooling and control conditions for precooling and percooling (all $\mathrm{p}$ values $>0.05$ ). Furthermore, no correlations were found between measures of performance and $\Delta \mathrm{Tc}$, $\Delta$ Tskin and $\Delta \mathrm{HR}$ for precooling, percooling and the pooled set of cooling studies (all $\mathrm{p}$ values $>0.05$ ).

\section{Different cooling techniques \\ Precooling}

We found that the effect of the different cooling strategies on exercise performance differed significantly across precooling techniques $(\mathrm{p}<0.001)$. Mixed method cooling $(+7.3 \%, \mathrm{ES}=0.72$, figure 3) demonstrated a significantly larger ES $(\mathrm{p}<0.01) \mathrm{com}-$ pared with cold water immersion $(+6.5 \%, \mathrm{ES}=0.49)$, cold water/ ice slurry ingestion $(+6.3 \%$, $\mathrm{ES}=0.40)$, cooling packs $(+4.3 \%$, $\mathrm{ES}=0.40)$ and cooling vests $(+3.4 \%, \mathrm{ES}=0.19$; table 2$)$.

\section{Percooling}

For percooling studies, three different cooling techniques were identified: ice vest, cold water ingestion and cooling packs (table 2). We found a significant difference in ES between the three percooling techniques in our meta-analysis $(p=0.01)$. Wearing an ice vest during exercise $(+21.5 \%, E S=4.64)$ was significantly more effective in improving exercise performance compared with cold water ingestion $(+11 \%, \mathrm{ES}=1.75)$ and cooling packs $(+8.4 \%, \mathrm{ES}=0.39)$ $(\mathrm{p}=0.02$, table 2$)$. 


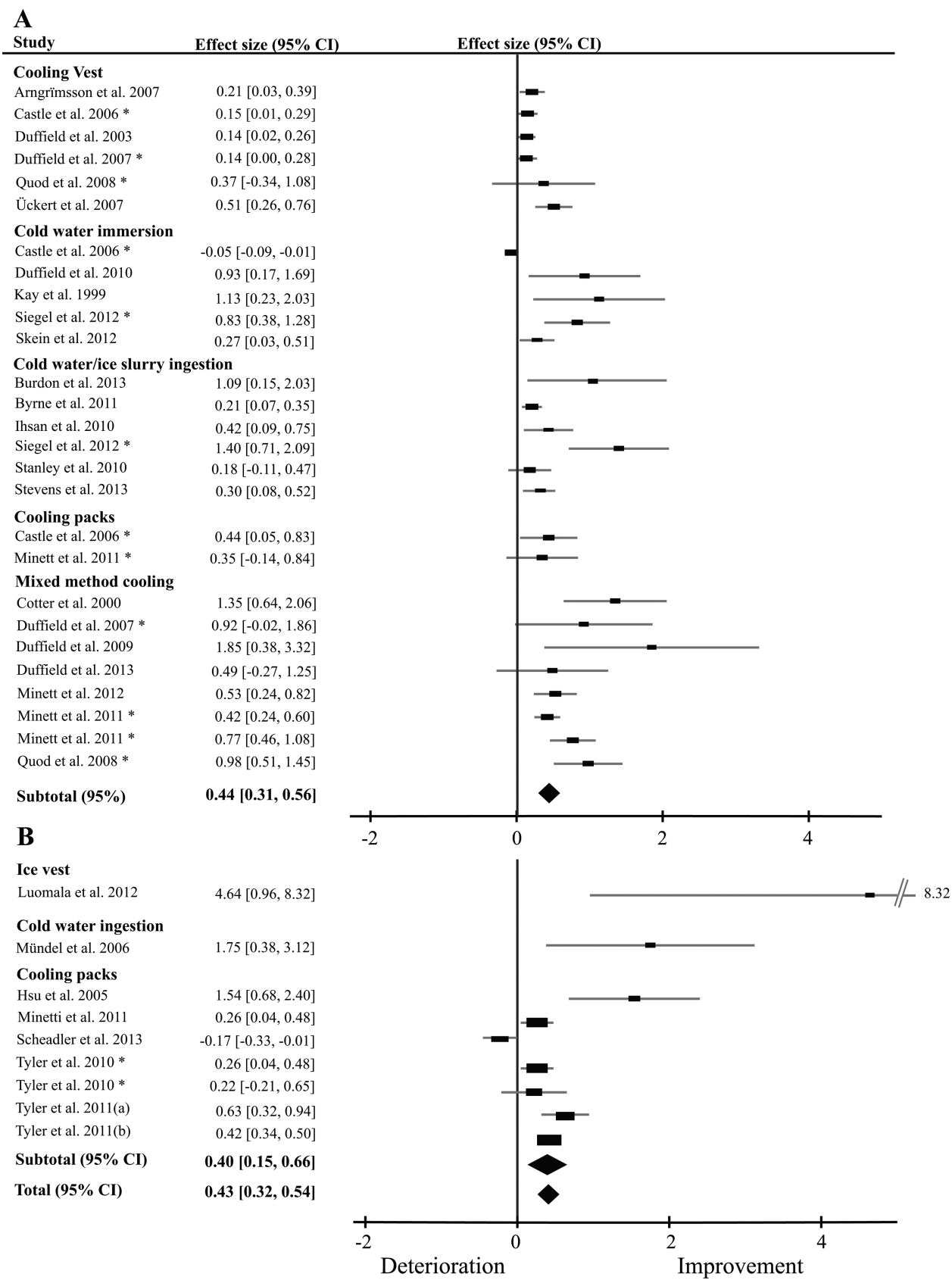

Figure 3 Forest plot summarising the effects of different cooling techniques on exercise performance for the precooling studies $(A)$ and the percooling studies (B). The magnitude of the effect size indicates: $0-0.19=$ negligible effect, $0.20-0.49=$ small effect, $0.50-0.79=$ moderate effect and $\geq 0.80=$ large effect. ${ }^{14}$ The black rectangles represented the weighted effect size and the grey lines are the $95 \%$ Cls. The size of the rectangles indicated the weight of the study, which is calculated separately for the precooling and percooling studies. * Studies that used multiple cooling intervention trials were included more than once.

\section{DISCUSSION}

The purpose of this meta-analysis was to (1) compare the effects of precooling versus percooling on exercise performance and thermophysiological reponses in the heat and (2) to identify the most effective cooling technique for improvement in exercise performance. Data review and analysis of the existing studies indicates that cooling significantly improves exercise performance, while the effect of cooling was similarly present between precooling and percooling. Second, thermophysiological (such as Tc, Tskin and HR) outcomes did not change in response to precooling and percooling, while no correlation was present between the change in thermophysiological measures and exercise performance. Third, we found significant differences between precooling techniques to improve exercise performance, with the use of a mixed method of cooling being the most effective. Such an effect between different techniques was also observed for percooling, with an ice vest being the most effective strategy. Taken together, cooling prior to or during exercise in the heat improves exercise performance with evidence supporting a superior effect of mixed methods for precooling and ice vests for percooling on performance levels in athletes, while these performance effects are unlikely to be related to a lower Tskin or Tc.

Our analysis summarises and demonstrates a significant effect of cooling interventions on exercise performance in healthy athletes under demanding thermal conditions. ${ }^{1744}$ We extend the current knowledge by the observation that the impact of 


\begin{tabular}{|c|c|c|c|c|c|c|c|c|c|c|c|}
\hline & & $\begin{array}{l}\text { Tc maximum } \\
\text { control }\end{array}$ & $\begin{array}{l}\text { Tc maximum } \\
\text { cooling }\end{array}$ & $\begin{array}{l}\Delta \mathrm{Tc} \\
\text { maximum }\end{array}$ & $\begin{array}{l}\text { Tskin maximum } \\
\text { control }\end{array}$ & $\begin{array}{l}\text { Tskin maximum } \\
\text { cooling }\end{array}$ & $\begin{array}{l}\Delta \text { Tskin } \\
\text { maximum }\end{array}$ & $\begin{array}{l}\text { HR maximum } \\
\text { control }\end{array}$ & $\begin{array}{l}\text { HR maximum } \\
\text { cooling }\end{array}$ & $\begin{array}{l}\Delta \mathrm{HR} \\
\text { maximum }\end{array}$ & $\begin{array}{l}\text { Performance } \\
(\%)\end{array}$ \\
\hline \multicolumn{12}{|l|}{ Precooling } \\
\hline \multirow[t]{3}{*}{ Cooling packs } & Castle et $a l^{18}$ & 39.1 & 38.4 & -0.7 & 36.9 & 36.4 & -0.5 & 179 & 181 & 2 & 4.3 \\
\hline & Minett et $a l^{27}$ & 39.1 & 39.1 & 0 & 34.0 & 34.2 & 0.2 & 173 & 175 & 2 & 4.3 \\
\hline & Weighted average & 39.1 & 38.8 & -0.4 & 35.5 & 35.3 & -0.1 & 176 & 178 & 2 & 4.3 \\
\hline \multirow[t]{7}{*}{ Cooling vests } & Arngrimsson et al ${ }^{11}$ & 39.8 & 39.6 & -0.2 & 34.2 & 34.5 & 0.3 & 195 & 195 & 0 & 1.3 \\
\hline & Castle et $a l^{18}$ & 39.1 & 38.9 & -0.2 & 36.9 & 36.6 & -0.3 & 179 & 184 & 5 & 1.5 \\
\hline & Duffield et $a l^{20}$ & 38.8 & 38.7 & -0.1 & 34.0 & 33.6 & -0.4 & NA & NA & NA & 2.4 \\
\hline & Duffield et $a l^{22}$ & 39.6 & 39.2 & -0.4 & 34.4 & 34.4 & 0 & 182 & 187 & 5 & 1.3 \\
\hline & Quod et $a l^{30}$ & 39.6 & 39.7 & 0.1 & 34.6 & 34.5 & -0.1 & 193 & 193 & 0 & 1.5 \\
\hline & Ückert et $a \beta^{36}$ & 38.8 & 38.4 & -0.4 & 35.6 & 35.1 & -0.5 & 192 & 190 & -2 & 7.3 \\
\hline & Weighted average & 39.3 & 39.1 & -0.2 & 35.0 & 34.8 & -0.2 & 188 & 190 & 2 & 3.4 \\
\hline \multirow{7}{*}{$\begin{array}{l}\text { Cold water } \\
\text { ingestion }\end{array}$} & Burdon et $\left.a\right|^{43}$ & 38.7 & 38.7 & 0.0 & 33.4 & 33.3 & -0.1 & 165 & 168 & 3 & 10.5 \\
\hline & Byrne et $a l^{37}$ & 38.6 & 38.1 & -0.5 & 35.4 & 35.1 & -0.3 & 190 & 189 & -1 & 2.9 \\
\hline & Ihsan et $a^{\beta 9}$ & 38.8 & 39.1 & 0.3 & 35.6 & 35.8 & 0.2 & NA & NA & NA & 6.9 \\
\hline & Siegel et $a l^{6}$ & 39.5 & 39.8 & 0.3 & 35.7 & 35.5 & -0.2 & 188 & 189 & 1 & 12.8 \\
\hline & Stanley et $a^{32}$ & 39.1 & 39.0 & -0.1 & NA & NA & NA & 191 & 191 & 0 & 1.9 \\
\hline & Stevens et $a^{42}$ & 39.0 & 38.2 & -0.8 & NA & NA & NA & NA & NA & NA & 2.8 \\
\hline & Weighted average & 39.0 & 38.8 & -0.1 & 35.0 & 34.9 & -0.1 & 184 & 184 & 1 & 6.3 \\
\hline \multirow[t]{8}{*}{$\begin{array}{l}\text { Mixed method } \\
\text { cooling }\end{array}$} & $\begin{array}{l}\text { Cotter et } a l^{19} \\
\text { Duffield et al }\end{array}$ & $\begin{array}{l}38.9 \\
39.6\end{array}$ & $\begin{array}{l}38.5 \\
39.0\end{array}$ & $\begin{array}{l}-0.4 \\
-0.6\end{array}$ & $\begin{array}{l}35.9 \\
34.4\end{array}$ & $\begin{array}{l}35.1 \\
34.0\end{array}$ & $\begin{array}{l}-0.8 \\
-0.4\end{array}$ & $\begin{array}{l}178 \\
182\end{array}$ & $\begin{array}{l}177 \\
187\end{array}$ & $\begin{array}{r}-1 \\
5\end{array}$ & $\begin{array}{r}15.2 \\
8.3\end{array}$ \\
\hline & Duffield et $a l^{23}$ & 39.3 & 38.8 & -0.5 & NA & NA & NA & 162 & 146 & -16 & 7.7 \\
\hline & Duffield et $a l^{38}$ & 39.0 & 38.9 & -0.1 & 34.6 & 34.8 & 0.2 & 182 & 186 & 4 & 3.0 \\
\hline & Minett et $\left.a\right|^{27}$ & 39.1 & 39.0 & -0.1 & 34.0 & 34.1 & 0.1 & 173 & 170 & -3 & 5.2 \\
\hline & Minett et $\left.a\right|^{27}$ & 39.1 & 38.7 & -0.4 & 34.0 & 33.1 & -0.9 & 173 & 169 & -4 & 9.5 \\
\hline & Minett et $a l^{12}$ & 39.1 & 38.7 & -0.4 & 33.9 & 33.1 & -0.8 & 178 & 170 & -8 & 4.7 \\
\hline & Quod et $a l^{30}$ & 39.6 & 39.5 & -0.1 & 34.6 & 33.8 & -0.8 & 193 & 192 & -1 & 4.0 \\
\hline & Weighted average & 39.1 & 38.9 & -0.3 & 34.5 & 34.0 & -0.5 & 178 & 175 & -3 & 7.3 \\
\hline \multirow[t]{5}{*}{$\begin{array}{l}\text { Cold water } \\
\text { immersion }\end{array}$} & $\begin{array}{l}\text { Castle et } a l^{18} \\
\text { Duffield et } a l^{21}\end{array}$ & $\begin{array}{l}39.1 \\
39.0\end{array}$ & $\begin{array}{l}38.8 \\
38.9\end{array}$ & $\begin{array}{l}-0.3 \\
-0.1\end{array}$ & $\begin{array}{l}36.9 \\
35.7\end{array}$ & $\begin{array}{l}34.5 \\
35.5\end{array}$ & $\begin{array}{l}-2.4 \\
-0.2\end{array}$ & $\begin{array}{l}179 \\
178\end{array}$ & $\begin{array}{l}175 \\
183\end{array}$ & $\begin{array}{r}-4 \\
5\end{array}$ & $\begin{array}{r}-0.5 \\
7.2\end{array}$ \\
\hline & Kay et $a l^{25}$ & 38.8 & 38.5 & -0.3 & 34.7 & 33.6 & -1.1 & 178 & 177 & -1 & 6.0 \\
\hline & Siegel et $a \beta^{31}$ & 39.5 & 39.5 & 0 & 35.7 & 35.3 & -0.4 & 188 & 190 & 2 & 21.6 \\
\hline & Skein et $a l^{41}$ & 38.9 & 38.7 & -0.2 & 31.5 & 33.1 & 1.6 & 180 & 182 & 2 & 2.4 \\
\hline & Weighted average & 39.1 & 38.9 & -0.2 & 34.9 & 34.4 & -0.5 & 181 & 181 & 1 & 6.5 \\
\hline \multirow[t]{2}{*}{ Total precooling } & Weighted average & 39.1 & 38.9 & -0.2 & 34.9 & 34.5 & -0.3 & 181 & 181 & 0 & 5.7 \\
\hline & Student $t$ test & 0.03 & & & 0.34 & & & 0.94 & & & \\
\hline \multicolumn{12}{|l|}{ Percooling } \\
\hline \multirow[t]{6}{*}{ Cooling packs } & Hsu et a ${ }^{24}$ & 38.4 & 38.1 & -0.3 & NA & NA & NA & 159 & 161 & 2 & 6.6 \\
\hline & Minitti et $a^{28}$ & NA & NA & NA & NA & NA & NA & NA & NA & NA & 5.4 \\
\hline & Scheadler et $a l^{40}$ & 39.2 & 39.4 & 0.2 & NA & NA & NA & 178 & 178 & 0 & -11.6 \\
\hline & Tyler et $a l^{35}$ & 39.3 & 39.1 & -0.1 & 35.0 & 35.6 & 0.6 & 186 & 188 & 2 & 5.1 \\
\hline & Tyler et $a l^{35}$ & 38.3 & 38.4 & 0.1 & 35.8 & 26.1 & -9.7 & 187 & 187 & 0 & 1.9 \\
\hline & Tyler et $a l^{\beta 3}$ & 39.2 & 39.7 & 0.5 & 35.6 & 27.6 & -8 & 181 & 178 & -3 & 7.0 \\
\hline
\end{tabular}




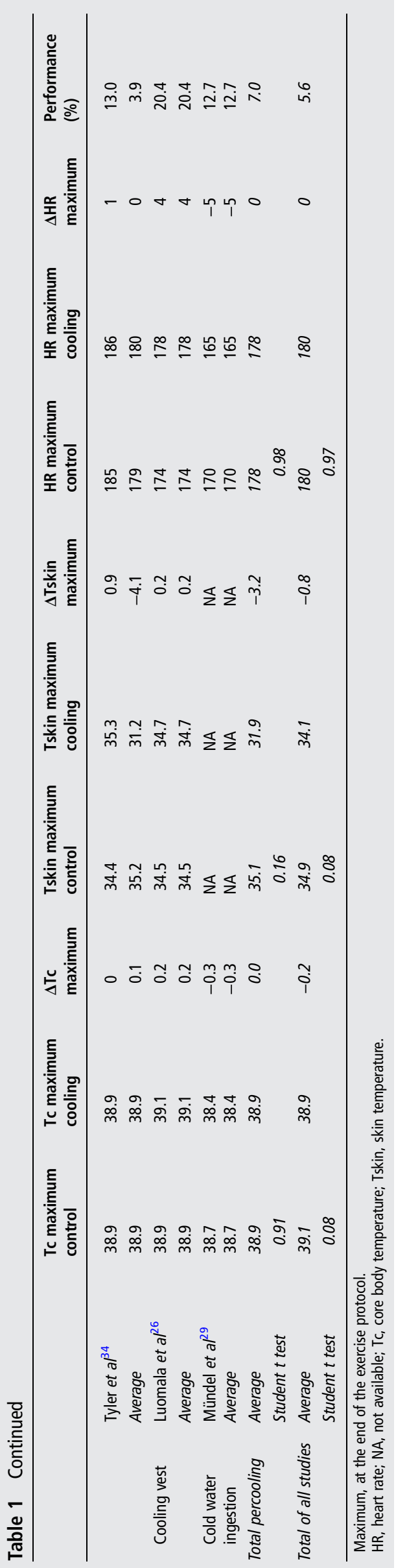

precooling and percooling on exercise performance is comparable. It is important to take note of the significant publication bias, which is demonstrated in the funnel plot (figure 2), suggesting that negative studies may not have been published. Although this could implicate an overestimation of the overall effect of cooling, there is still abundant evidence that cooling effectively improves exercise performance when exercise is performed in the heat. The application of precooling and percooling are therefore recommended to improve exercise performance while exercising in hot ambient conditions.

Although our statistical analysis does not support a difference in ES between precooling and percooling ( $E S=0.44$ vs 0.40 ), the variation in performance enhancement between precooling $(+5.7 \%)$ and percooling $(+9.9 \%)$ is large. It is believed that both cooling strategies achieve their effects through comparable underlying mechanisms. It is known that exercise leads to a significant level of thermal strain due to a large increase in heat production in the exercising muscles. Maintaining an adequate heat balance requires a significant amount of energy for heat dissipating mechanisms, such as (skin) vasodilation and sweating responses. ${ }^{94}$ Percooling contributes to a higher heat storage capacity, a more efficient heat loss and may attenuate the increase in Tc. The attenuated increase in Tc may prevent a decrease in exercise performance. The purpose of precooling is to lower Tc before starting the exercise, leading to an increase in heat storage capacity during exercise. It is hypothesised that the larger heat buffer, induced by precooling, enables the body to perform more work prior to reaching a critical limit for Tc. ${ }^{13}$ This suggests that precooling and percooling enhance exercise performance. Accordingly, we hypothesise that a combination of precooling and percooling may be more effective in improving exercise performance than a single cooling strategy only. Until now, only one pilot study $(n=9)$ has examined this hypothesis and shown that combined precooling and percooling is superior in improving exercise performance compared with precooling or percooling alone. ${ }^{46}$ Future studies may be aimed at further exploring the combined effect of precooling and percooling on exercise performance.

One important question that this meta-analysis tried to answer was whether the impact of cooling strategies can be explained through its effects on thermophysiological factors. Precooling resulted in a significantly lower finishing $\mathrm{Tc}$ in the cooling condition compared with the control, while this finding was absent in percooling studies. Presumably, percooling attenuated the increase in Tc and thus increased the heat storage capacity. For this reason, athletes were able to produce more heat before terminating the exercise or lowering the exercise intensity, which results in performance enhancements. ${ }^{10} 33$ Likewise, we did not find correlations between the change in physiological parameters and the improvement of performance (figure 4). These findings suggest that a lower Tc at the end of the exercise does not necessarily improve exercise performance in the heat. It is more likely that the cooling interventions resulted in a reduction of the rise in physiological parameters, which enabled athletes to exercise at a higher absolute amount of work resulting in an improved performance but a comparable finishing Tc, Tskin and HR. ${ }^{5}$

None of the included studies reported any thermoregulatory problems or heat-related illnesses among their participants. This may imply that our body applies internal protection mechanisms to avoid reaching a critical high temperature. There are two common hypotheses that may explain this thermal behaviour. First, as Tc becomes elevated, exercise will be terminated once critically high internal temperatures are attained, which is a safeguard that limits the potential development of dangerous heat illness. ${ }^{5}$ Second, the rate of heat gain is detected by our body, 
Table 2 Overview of subtotal effect sizes $\pm 95 \% \mathrm{Cl}$ of different cooling techniques for the precooling and percooling interventions

\begin{tabular}{lllll}
\hline & Number of studies & Precooling & Number of studies & Percooling \\
\hline Cooling vest & 6 & $0.19(0.10$ to 0.28$)$ & 1 & $4.64(0.96$ to 8.32$)$ \\
Cold water immersion & 5 & $0.49(0.09$ to 0.90$)$ & - & NA \\
Cold water ingestion & 6 & $0.40(0.17$ to 0.62$)$ & 1 & $1.75(0.38$ to 3.12$)$ \\
Cooling packs & 2 & $0.40(0.10$ to 0.71$)$ & - & $0.34(0.09$ to 0.58$)$ \\
Mixed method cooling & 8 & $0.72(0.49$ to 0.96$)$ & NA \\
Average effect size & 27 & $0.44(0.31$ to 0.56$)$ & 9 & $0.40(0.15$ to 0.66$)$
\end{tabular}

NA, not available.

Figure 4 Correlations between change in exercise performance (\%) and change in core temperature $(\Delta \mathrm{Tc})$, skin temperature ( $\Delta$ Tskin) and heart rate $(\Delta \mathrm{HR})$ for precooling $(\mathbf{O})$ and percooling (O). Pearson's correlation coefficient, significance assumed at $\mathrm{p}<0.05 . \Delta=$ cooling-control.
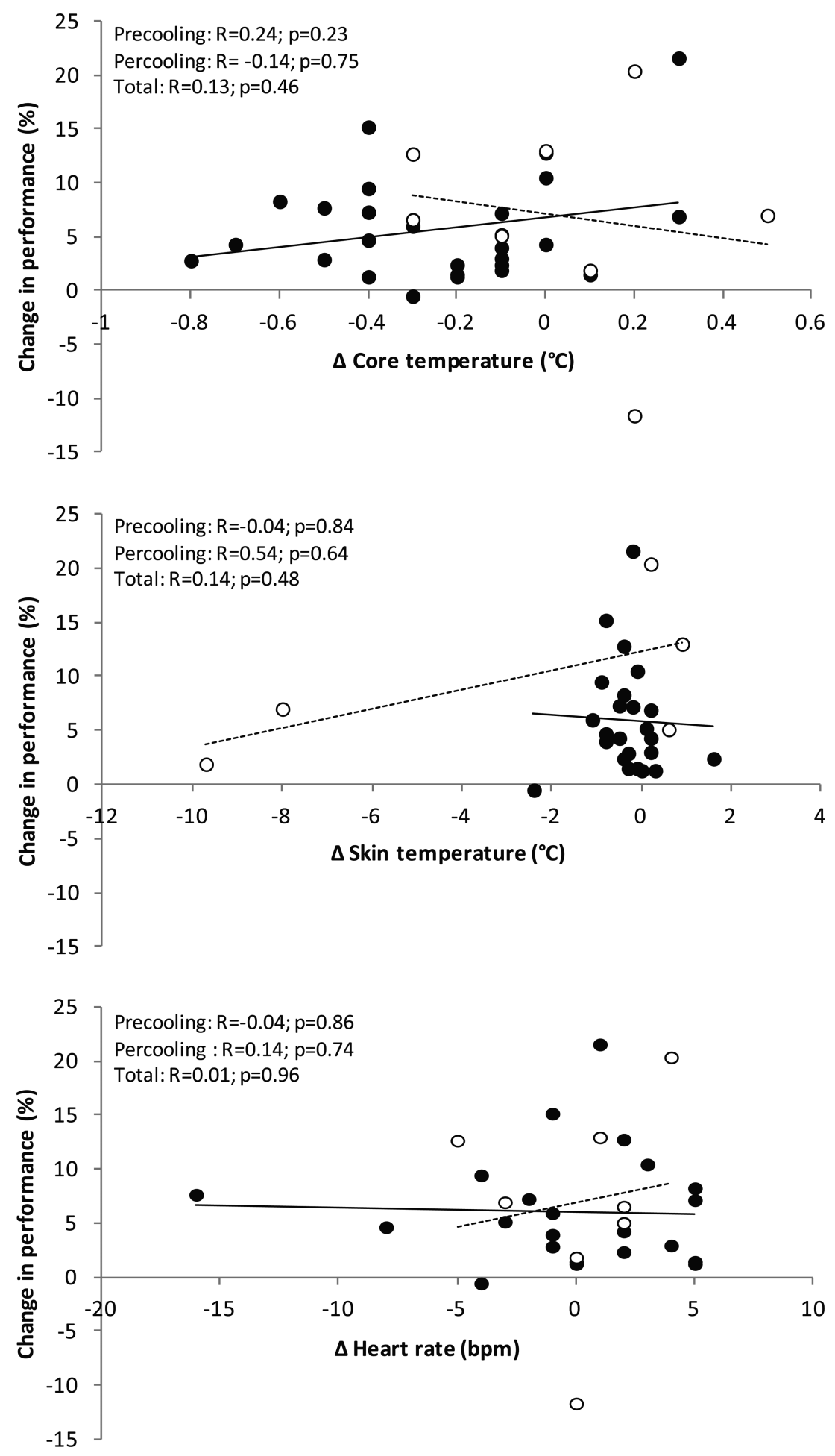
which could anticipatorily adjust the work rate to ensure that the exercise task can be completed within the homeostatic limits of the body. ${ }^{57}$ As this meta-analysis included merely information about peak Tc, we could not test which hypothesis was adopted by athletes while performing exercise in the heat. Future studies that compare the threshold with the anticipatory theory are recommended, so that appropriate cooling techniques can be selected accordingly.

This meta-analysis demonstrated a significant impact of the type of cooling strategy when performing precooling to enhance exercise performance. Our analysis revealed that a combination of techniques (ie, mixed method precooling) had a significantly larger effect than individual cooling techniques (cold water/ice slurry ingestion, cooling vests, cooling packs or cold water immersion alone). This observation is reinforced by a study which examined three precooling strategies: (1) cooling pack, (2) cooling pack + cold water immersion and (3) cooling pack + cold water immersion + ice vest. ${ }^{27}$ While no effect was found for the cooling pack, both mixed method cooling trials effectively improved exercise performance. ${ }^{27}$ The higher cooling capacity in the mixed method cooling compared with individual cooling strategies most likely contributes to this finding. Mixed techniques with an 'aggressive' approach and affecting a large body surface especially seem to contribute to a larger effect on exercise performance. The law of enthalpy of fusion states that ice possesses a significantly greater capacity to absorb heat than liquid water. ${ }^{6} 4849$ Accordingly, more aggressive cooling techniques, typically depending on ice or substances with a temperature below zero, demonstrate a larger effect on changing $T c$ and/or exercise performance. In addition, previous data support the idea that whole body cooling is more effective than cooling of a part of the body only. ${ }^{27}$ Indeed, despite the use of a relatively mild stimulus (ie, $14-24^{\circ} \mathrm{C}$ ), full body water immersion significantly improved exercise performance. ${ }^{18} 212531$ The large cooling surface may importantly contribute to the prolonged suppression of increased physiological and thermal loads $^{22} 50$ and thus improve exercise performance. Taken together, a combination of precooling techniques, preferably 'aggressive' cooling and interventions that cover a substantial part of the athlete's body, represents the current 'best practice' model for precooling to improve exercise performance.

Also, for the percooling strategies, our meta-analysis revealed a significant impact of the type of cooling. Our analyses indicate that wearing an ice vest during exercise has a significantly larger effect than other percooling techniques (cold water ingestion and cooling packs). Interestingly, the ice vests represent an aggressive cooling strategy that impacts on a relatively large body surface. This provides further support that also during percooling, strategies with an aggressive nature that aim at a relatively large body surface area are the most effective cooling strategies. An important limitation is that we only included a single study on the impact of an ice vest, which coincidentally reported a remarkably large ES. Nonetheless, the similarities between the type of most effective cooling strategies for precooling and percooling are striking. We strongly support future studies to confirm this finding using not only well-controlled, within participants designs, but also to improve our understanding why and how these aggressive types of cooling are more successful.

\section{Practical recommendations}

Our meta-analysis combined the results of 323 participants in 28 peer-reviewed publications and demonstrated the practical value of cooling strategies to improve exercise performance in the heat.
More importantly, we showed that precooling and percooling are equally effective in improving exercise performance in the heat. Therefore, a combination of precooling and percooling may be superior compared with a single strategy alone. Moreover, we revealed that a combination of cooling techniques (for precooling) or ice vests (for percooling) results in the largest ES on exercise performance, possibly due to the aggressive approach and impact on a relatively large body surface. Based on our novel observations, we recommend future studies to investigate the practical performance and ES of combining precooling and percooling strategies on exercise performance, preferably using aggressive types of strategies. Such joint efforts can further improve exercise performance in the heat, while it may also contribute to a reduction in heat-related illnesses in athletes.

\section{What are the new findings?}

- Precooling and percooling are equally effective in improving exercise performance in the heat.

- No correlations were found between measures of performance and change in core body temperature, skin temperature and heart rate $(\Delta \mathrm{Tc}, \Delta \mathrm{Tskin}$ and $\Delta \mathrm{HR})$ for precooling, percooling and the pooled set of cooling studies.

- A combination of cooling techniques (for precooling) or ice vests (for percooling) are preferred to improve exercise performance in the heat.

- The combination of precooling and percooling techniques could be the most effective strategy to improve exercise performance in the heat.

Acknowledgements We are grateful to all the authors who provided additional data for this meta-analysis which were not included in their original publications.

Contributors CCWGB, TMHE and MTEH designed the study. CCWGB, DHJT and TMHE performed the literature search and selected the included studies. MTWV and CCWGB performed the statistical analysis, and all authors contributed to data interpretation. CCWGB and TMHE drafted the manuscript, while MTWV, DHJT and MTEH critically revised the article. All authors gave their final approval of the version published.

Competing interests TMHE is financially supported by the Netherlands Organization for Scientific Research (Rubicon Grant 825.12.016) and DHJT received an E-Dekker stipend from the Dutch Heart Foundation (2009T064).

Provenance and peer review Not commissioned; externally peer reviewed.

\section{REFERENCES}

1 Duffield R. Cooling interventions for the protection and recovery of exercise performance from exercise-induced heat stress. Med Sport Sci 2008;53:89-103.

2 Wendt $D$, van Loon LJ, Lichtenbelt WD. Thermoregulation during exercise in the heat: strategies for maintaining health and performance. Sports Med 2007;37:669-82.

3 Maughan R, Shirreffs S. Exercise in the heat: challenges and opportunities. J Sports Sci 2004;22:917-27.

4 Marino FE. Methods, advantages, and limitations of body cooling for exercise performance. Br J Sports Med 2002;36:89-94.

5 Quod MJ, Martin DT, Laursen PB. Cooling athletes before competition in the heat: comparison of techniques and practical considerations. Sports Med 2006;36:671-82

6 Siegel R, Laursen PB. Keeping your cool: possible mechanisms for enhanced exercise performance in the heat with internal cooling methods. Sports Med 2012:42:89-98.

7 Wegmann M, Faude 0, Poppendieck W, et al. Pre-cooling and sports performance: a meta-analytical review. Sports Med 2012;42:545-64.

8 Bolster DR, Trappe SW, Short KR, et al. Effects of precooling on thermoregulation during subsequent exercise. Med Sci Sports Exerc 1999;31:251-7.

9 Kenefick RW, Cheuvront SN, Sawka MN. Thermoregulatory function during the marathon. Sports Med 2007;37:312-15. 
10 Tyler CJ, Sunderland C, Cheung SS. The effect of cooling prior to and during exercise on exercise performance and capacity in the heat: a meta-analysis. Br J Sports Med 2015;49:7-13.

11 Arngrïmsson SA, Petitt DS, Stueck MG, et al. Cooling vest worn during active warm-up improves 5-km run performance in the heat. J Appl Physiol 2004:96:1867-74.

12 Minett GM, Duffield R, Marino FE, et al. Duration-dependant response of mixed-method pre-cooling for intermittent-sprint exercise in the heat. Eur J Appl Physiol 2012;112:3655-66.

13 Stannard $A B$, Brandenburg JP, Pitney WA, et al. Effects of wearing a cooling vest during the warm-up on 10-km run performance. J Strength Cond Res 2011:25:2018-24.

14 Cohen J. Statistical power analysis for the behavioral sciences. 2nd edn. Hillsdale, NJ: Lawrence Erlbaum Associates, 1988: 567.

15 Begg CB, Mazumdar M. Operating characteristics of a rank correlation test for publication bias. Biometrics 1994;50:1088-101.

16 Egger M, Davey Smith G, Schneider M, et al. Bias in meta-analysis detected by a simple, graphical test. BMJ 1997;315:629-34.

17 Sterne JA, Egger $M$, Smith GD. Systematic reviews in health care: investigating and dealing with publication and other biases in meta-analysis. BMJ 2001;323:101-5.

18 Castle PC, Macdonald AL, Philp A, et al. Precooling leg muscle improves intermittent sprint exercise performance in hot, humid conditions. J App/ Physiol 2006;100:1377-84.

19 Cotter JD, Sleivert GG, Roberts WS, et al. Effect of pre-cooling, with and without thigh cooling, on strain and endurance exercise performance in the heat. Comp Biochem Physiol A Mol Integr Physiol 2001;128:667-77.

20 Duffield R, Dawson B, Bishop D, et al. Effect of wearing an ice cooling jacket on repeat sprint performance in warm/humid conditions. Br J Sports Med 2003;37:164-9.

21 Duffield R, Green R, Castle P, et al. Precooling can prevent the reduction of self-paced exercise intensity in the heat. Med Sci Sports Exerc 2010;42:577-84.

22 Duffield R, Marino FE. Effects of pre-cooling procedures on intermittent-sprint exercise performance in warm conditions. Eur J Appl Physiol 2007;100:727-35.

23 Duffield R, Steinbacher G, Fairchild TJ. The use of mixed-method, part-body pre-cooling procedures for team-sport athletes training in the heat. I Strength Cond Res 2009;23:2524-32.

24 Hsu AR, Hagobian TA, Jacobs KA, et al. Effects of heat removal through the hand on metabolism and performance during cycling exercise in the heat. Can J App/ Physiol 2005;30:87-104.

25 Kay D, Taaffe DR, Marino FE. Whole-body pre-cooling and heat storage during self-paced cycling performance in warm humid conditions. J Sports Sci 1999:17:937-44.

26 Luomala MO Jr, Salmi J, Linnamo V, et al. Adding adding adding vest during cycling improves performance in warm and humid conditions. J Thermal Biol 2012;37:47-55.

27 Minett GM, Duffield R, Marino FE, et al. Volume-dependent response of precooling for intermittent-sprint exercise in the heat. Med Sci Sports Exerc 2011;43:1760-9.

28 Minniti A, Tyler CJ, Sunderland C. Effects of a cooling collar on affect, ratings of perceived exertion, and running performance in the heat. Eur J Sport Sci 2011:11:419-29.

29 Mündel T, King J, Collacott E, et al. Drink temperature influences fluid intake and endurance capacity in men during exercise in a hot, dry environment. Exp Physiol 2006;91:925-33.
30 Quod MJ, Martin DT, Laursen PB, et al. Practical precooling: effect on cycling time trial performance in warm conditions. J Sports Sci 2008;26:1477-87.

31 Siegel R, Mate J, Watson G, et al. Pre-cooling with ice slurry ingestion leads to similar run times to exhaustion in the heat as cold water immersion. J Sports Sci 2012;30:155-65

32 Stanley J, Leveritt M, Peake JM. Thermoregulatory responses to ice-slush beverage ingestion and exercise in the heat. Eur J Appl Physiol 2010;110:1163-73.

33 Tyler CJ, Sunderland C. Cooling the neck region during exercise in the heat. J Athl Train 2011;46:61-8.

34 Tyler CJ, Sunderland C. Neck cooling and running performance in the heat: single versus repeated application. Med Sci Sports Exerc 2011;43:2388-95.

35 Tyler CJ, Wild P, Sunderland C. Practical neck cooling and time-trial running performance in a hot environment. Eur J App/ Physiol 2010;110:1063-74.

36 Ückert $S$, Joch W. Effects of warm-up and precooling on endurance performance in the heat. Br J Sports Med 2007;41:380-4.

37 Byrne C, Owen C, Cosnefroy A, et al. Self-paced exercise performance in the heat after pre-exercise cold-fluid ingestion. J Athl Train 2011;46:592-9.

38 Duffield R, Coutts A, McCall A, et al. Pre-cooling for football training and competition in hot and humid conditions. Eur J Sport Sci 2013;13:58-67.

39 Ihsan $M$, Landers $G$, Brearley $M$, et al. Beneficial effects of ice ingestion as a precooling strategy on 40-km cycling time-trial performance. Int J Sports Physiol Perform 2010;5:140-51.

40 Scheadler CM, Saunders NW, Hanson NJ, et al. Palm cooling does not improve running performance. Int J Sports Med 2013;34:732-5.

41 Skein M, Duffield R, Cannon J, et al. Self-paced intermittent-sprint performance and pacing strategies following respective pre-cooling and heating. Eur J Appl Physiol 2012;112:253-66.

42 Stevens CJ, Dascombe B, Boyko A, et al. Ice slurry ingestion during cycling improves Olympic distance triathlon performance in the heat. J Sports Sci 2013;31:1271-9.

43 Burdon CA, Hoon MW, Johnson NA, et al. The effect of ice slushy ingestion and mouthwash on thermoregulation and endurance performance in the heat. Int $J$ Sport Nutr Exerc Metab 2013;23:458-69.

44 Jones PR, Barton C, Morrissey D, et al. Pre-cooling for endurance exercise performance in the heat: a systematic review. BMC Med 2012;10:166.

45 Reilly T, Drust B, Gregson W. Thermoregulation in elite athletes. Curr Opin Clin Nutr Metab Care 2006;9:666-71.

46 Hasegawa $H$, Takatori $T$, Komura $T$, et al. Combined effects of pre-cooling and water ingestion on thermoregulation and physical capacity during exercise in a hot environment. J Sports Sci 2006;24:3-9.

47 Tucker R, Rauch L, Harley YX, et al. Impaired exercise performance in the heat is associated with an anticipatory reduction in skeletal muscle recruitment. Pflugers Arch 2004;448:422-30.

48 Merrick MA, Jutte LS, Smith ME. Cold modalities with different thermodynamic properties produce different surface and intramuscular temperatures. J Athl Train 2003;38:28-33.

49 Yeo ZW, Fan PW, Nio AQ, et al. Ice slurry on outdoor running performance in heat. Int J Sports Med 2012;33:859-66.

50 Daanen HA, van Es EM, de Graaf JL. Heat strain and gross efficiency during endurance exercise after lower, upper, or whole body precooling in the heat. Int J Sports Med 2006;27:379-88. 